\title{
Generalized arterial calcification of infancy
}

INSERM

\section{Source}

INSERM. (1999). Orphanet: an online rare disease and orphan drug data base.

Generalized arterial calcification of infancy. ORPHA:51608

\begin{abstract}
A rare genetic vascular disease characterized by early onset (between in utero to infancy) of extensive calcification and stenosis of the large and medium sized arteries.

Presentation is typically with respiratory distress, congestive heart failure and systemic hypertension.
\end{abstract}

